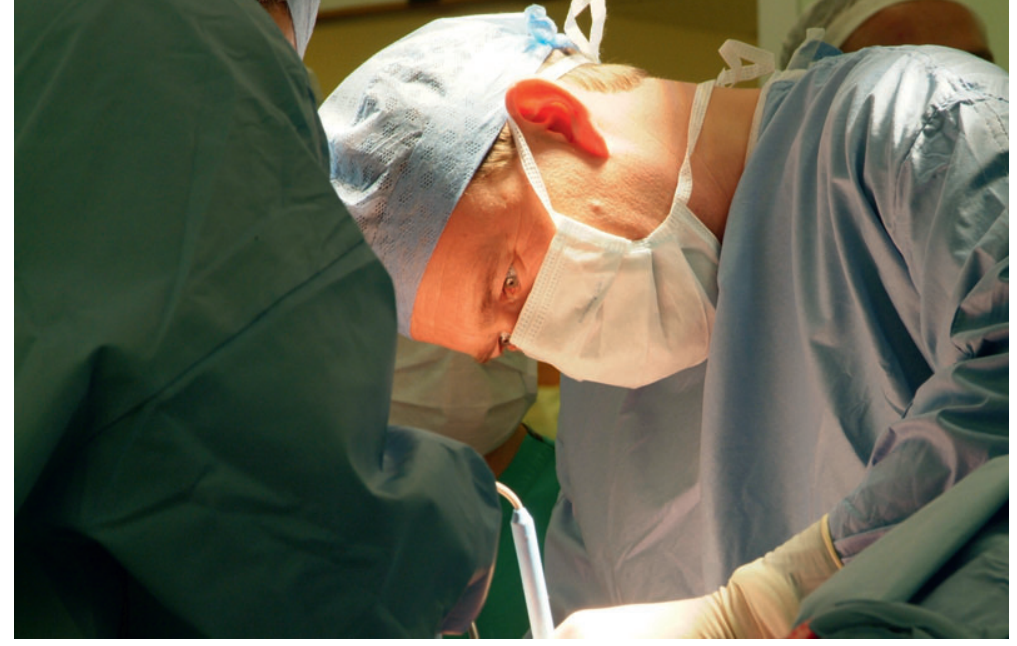

\title{
Insights
}

\section{Strategic questioning in surgical education}

\section{Christopher Magas ${ }^{1}$, Priya Dedhia ${ }^{1}$, Meredith Barrett ${ }^{1}$, Paul Gauger ${ }^{1}$, Larry Gruppen ${ }^{2}$ and Gurjit Sandhu ${ }^{1,2}$}

${ }^{1}$ Department of Surgery, University of Michigan Health System, Ann Arbor, Michigan, USA 2Department of Learning Health Sciences, University of Michigan Medical School, Ann Arbor, Michigan, USA

\section{Conscious \\ Socratic \\ LEARNER-CENTRED QUESTIONING}

questioning

contributes to a

culture of

educational

investment and

respect

Tr $\mathrm{n}$ the complex and nuanced world of surgical education, one-way teaching - often in the form of directives from the attending physician to the resident (i.e. from specialist to trainee) - is insufficient for understanding the needs of trainees and developing safe opportunities for learner advancement. We propose a novel learner-centred approach to intra-operative teaching using questioning that integrates: (1) Socratic questioning and (2) Bloom's Taxonomy, which respectively incorporates wait time and progressively complex questioning to stimulate higherorder thinking. ${ }^{1-4}$ As surgical faculty members, surgical residents and medical educators, we collaborate on this action-oriented initiative to enhance trainee education. The need for this multidimensional team approach has become particularly important in the context of educational time constraints, as a side effect of trainee work-hour restrictions and the exponential growth in surgical innovations, interventions and technologies.

Although questions are asked during surgical teaching, we found through our experiences and observations that an intentional Socratic method is rarely employed. A more common expression of this strategy was to 'keep asking questions, any questions.' Conscious Socratic questioning contributes to a culture of educational investment and respect that allows trainees to progress efficiently. ${ }^{5}$ Socratic principles for questioning have been defined by instances when the educator carefully constructs a series of questions that promote learner awareness and growth. By crafting a response, the learner demonstrates understanding, gains insight into knowledge limitations, and becomes comfortable in the face of uncertainty, thereby maximising the educational value of the operative experience. ${ }^{1}$

Additional aspects of the Socratic method - wait time and probing - contribute to a learner-centred environment. When using the wait-time technique, faculty members pause for 3-5 seconds after posing a question to provide the learner with time to frame a thoughtful answer, instead of the usual 1 second. ${ }^{2}$ This additional time promotes higher-order thinking and contributes to the retention 
of knowledge. ${ }^{2}$ Use of the probing technique judiciously challenges the trainee to provide a correct answer when the trainee is initially unable to do so. Using these techniques, the faculty member first identifies knowledge gaps then bridges these gaps using a progression of questions, from foundational knowledge to more complex and higher-order questions, in order to advance the understanding of the learner. ${ }^{2,4}$

\section{STRATEGIC QUESTIONING}

When working 'at the elbow' in the operating room, the faculty surgeon has a one-to-one learner-centred opportunity to sharpen a trainee's technical skills in addition to problem-solving and decision-making abilities. This is an ideal time to observe, listen to and query the trainee. Implementation of Bloom's Taxonomy, which is commonly used to classify learning objectives, provides a framework for developing questions to advance learners through increasingly complex and higher-order thinking. ${ }^{3}$ The foundational level in Bloom's Taxonomy is remembering. Each subsequent level (understanding, applying, analysing and assessing) is built on previous levels (Table 1).
The following questions illustrate strategic questioning in a hernia repair case. Questions at the remembering level typically include the recall of specific facts (e.g. 'What is the most common type of inguinal hernia?').

Understanding questions require learners to put facts together (e.g. 'Where does an indirect hernia occur?'). Applying questions examine the application of plans (e.g. 'What approach would you use to assess for an incarcerated inguinal hernia?'). Analysing questions have learners converge and diverge information for deeper investigation (e.g.

\section{Table 1. Strategic questioning based on Bloom's Taxonomy}

\begin{tabular}{|c|c|c|}
\hline Categories & Key Verbs & Sample Questions \\
\hline $\begin{array}{l}\text { 1. Remembering } \\
\text { Remember foundational } \\
\text { principles and recall facts }\end{array}$ & $\begin{array}{l}\text { Identify } \\
\text { List } \\
\text { Name }\end{array}$ & $\begin{array}{l}\text { How many...? } \\
\text { Where is...? } \\
\text { What is...? } \\
\text { What is the most common cause of duodenal } \\
\text { ulcer? }\end{array}$ \\
\hline $\begin{array}{l}\text { 2. Understanding } \\
\text { Understanding results and } \\
\text { following guidelines }\end{array}$ & $\begin{array}{l}\text { Explain } \\
\text { Interpret } \\
\text { Illustrate }\end{array}$ & $\begin{array}{l}\text { What is an example of...? } \\
\text { Explain in your own words, what does the...? } \\
\text { Describe what is happening when...? } \\
\text { How would you assess for a duodenal ulcer? }\end{array}$ \\
\hline $\begin{array}{l}\text { 3. Applying } \\
\text { Use knowledge and } \\
\text { understanding in concrete } \\
\text { situations to carry out steps or } \\
\text { plan }\end{array}$ & $\begin{array}{l}\text { Apply } \\
\text { Demonstrate } \\
\text { Use }\end{array}$ & $\begin{array}{l}\text { What questions would you ask the...? } \\
\text { What approach would you use to...? } \\
\text { What is another way to...? } \\
\text { A patient presents with burning epigastric pain } \\
3 \text { hours after eating, which improves with } \\
\text { eating. What is your initial treatment? }\end{array}$ \\
\hline $\begin{array}{l}\text { 4. Analysing } \\
\text { Differentiate information and } \\
\text { organise into meaningful } \\
\text { pattern }\end{array}$ & $\begin{array}{l}\text { Analyse } \\
\text { Compare and } \\
\text { contrast } \\
\text { Predict }\end{array}$ & $\begin{array}{l}\text { How does this compare to...? } \\
\text { What would happen if...? } \\
\text { How could this affect...? } \\
\text { What if the patient presented with a perforated } \\
\text { duodenal ulcer? }\end{array}$ \\
\hline $\begin{array}{l}\text { 5. Assessing } \\
\text { Justify and defend decision }\end{array}$ & $\begin{array}{l}\text { Critique } \\
\text { Judge } \\
\text { Justify }\end{array}$ & $\begin{array}{l}\text { Why did you choose...? } \\
\text { What changes would you recommend for...? } \\
\text { How would you have handled...? } \\
\text { Why, or why not, would you perform an acid- } \\
\text { reducing or drainage procedure in a patient } \\
\text { with a perforated duodenal ulcer? }\end{array}$ \\
\hline
\end{tabular}


Strategic questioning benefits the learning needs

of trainees

while

simultaneously advancing safe patient care
'What would you do if you found necrotic bowel when performing a hernia repair?'). Finally, assessing questions call for critical judgment (e.g. 'If you found the necrotic bowel was caused by a femoral hernia, how would your repair change?').

Bloom's Taxonomy provides educators with a framework for establishing questions that are appropriate for the learner. Consequently, not every Bloom's Taxonomy level may be used in a particular educational encounter. Surgical faculty members and residents on our team found that faculty members develop questions at different levels along Bloom's Taxonomy based on prior operative experiences with a trainee. This approach led to the scaffolding of resident education to incrementally higher cognitive levels. ${ }^{2-4}$ Accordingly, as residents progress and become increasingly proficient, questions increase in complexity and higher-order thinking. It is at these higher levels that learners process and integrate new information into existing cognitive frameworks with greater depth. ${ }^{2,3}$

In general, strategic questioning is a core pedagogical technique used in surgical education. Whether it is in the context of the operating room, out-patient clinic, morbidity and mortality conference, or attending rounds, trainees are constantly learning through answering questions. Here we have focused on strategic questioning in surgical education; however, the deliberate development of questions is applicable to all clinical educators because it: (1) supports the alignment of learning goals between faculty members and trainees; (2) identifies gaps and strengths to appropriately advance resident knowledge; and (3) requires active learnercentred interactions. Enhancing residency education with teaching methods that include strategic questioning benefits the learning needs of trainees while simultaneously advancing safe patient care.

\section{REFERENCES}

1. Haizlip J, May N, Schorling J, Williams A, Plews-Ogan M. Perspective: the negativity bias, medical education, and the culture of academic medicine: why culture change is hard. Acad Med 2012;87:1205-1209.

2. Hunkins FP. Teaching thinking through effective questioning. Boston: Christopher-Gordon Publishers, Inc.; 1995.

3. Bloom BS. Taxonomy of educational objectives; the classification of educational goals. New York: D. McKay Co., Inc.; 1974.

4. Beckman TJ, Lee MC. Proposal for a collaborative approach to clinical teaching. Mayo Clin Proc 2009;84:339-344.

5. Kost A, Chen FM. Socrates was not a pimp: changing the paradigm of questioning in medical education. Acad Med 2015;90:20-24.

Corresponding author's contact details: Dr Gurjit Sandhu, Department of Surgery, University of Michigan Health System, Ann Arbor, MI 48109, USA. E-mail: gurjit@umich.edu

Funding: None.

Conflict of interest: None.

Acknowledgements: None.

Ethical approval: Not required.

doi: 10.1111/tct.12525 